\title{
The benefit of atrial septal defect closure in elderly patients*
}

\author{
This article was published in the following Dove Press journal: \\ Clinical Interventions in Aging \\ 16 July 2014 \\ Number of times this article has been viewed
}

\section{Monika Komar \\ Tadeusz Przewlocki \\ Maria Olszowska \\ Bartosz Sobien \\ Piotr Podolec}

Department of Cardiac and Vascular Diseases, Institute of Cardiology, Jagiellonian University, Krakow, Poland
Objective: Closure of an atrial septal defect in elderly patients is controversial. The aim of the study was to evaluate the outcomes of transcatheter closure of secundum atrial septal defects (ASDs) in elderly patients.

Patients and methods: From a total of 488 patients with ASDs who underwent transcatheter closure, 75 patients aged over 60 years (45 female, 30 male) with a mean age of $65.3 \pm 15.7$ (60-75) years were analyzed. All patients had an isolated secundum ASD with a mean pulmonary blood flow:systemic blood flow of 2.84 \pm 1.9 (1.5-3.9). Symptom-limited treadmill exercise tests with respiratory gas-exchange analysis and transthoracic color Doppler echocardiographic study, as well as quality of life measured using the Short Form (36) Health Survey (SF-36) were repeated in all patients before the procedure and after 12 months of follow-up.

Results: The atrial septal device was successfully implanted in all patients (procedure time $37.7 \pm 4.5$ [13-59] minutes, fluoroscopy time $11.2 \pm 9.9$ [6-40] minutes). There were no major complications. The defect echo diameter was 17.7 $\pm 15.8(12-30) \mathrm{mm}$. The mean balloon-stretched diameter of ASDs was $22.4 \pm 7.9$ (14-34) $\mathrm{mm}$. The diameter of the implanted devices ranged from 16 to $34 \mathrm{~mm}$. Significant improvement of exercise capacity was noted at 6 and 12 months after the procedure. Exercise time within 6 months of ASD closure was longer $(P<0.001)$ compared to baseline values, and also oxygen consumption increased $(P<0.001)$. Seven quality-of-life parameters (except mental health) improved at 12-month follow-up compared to baseline data. The mean SF-36 scale increased significantly in $66(88 \%)$ patients, with a mean of $46.2 \pm 19.1$ (5-69). As early as 1 month after the procedure, a significant decrease of the right ventricular dimension and the right atrium dimension was observed $(P<0.001)$. The right ventricular dimension decreased in 67 patients $(89.3 \%)$.

Conclusion: Closure of ASDs in elderly patients caused significant clinical and hemodynamic improvement after percutaneous treatment, which was maintained during long-term follow-up, justifying this procedure in old age.

Keywords: atrial septal defect, transcatheter closure, elderly, cardiopulmonary exercise test, quality of life

\section{Introduction}

Atrial septal defects (ASDs) may not uncommonly remain undiagnosed until adulthood. The most common presenting symptoms at adult age are palpitations and exercise intolerance manifested as either exertional dyspnea or fatigue, which increase with age. ${ }^{1-3}$ More serious complications are typically seen in older patients with previously unrecognized ASDs who have been exposed to large left-to-right shunting for a long period. ${ }^{4,5}$ Closure of an ASD in patients with a hemodynamically significant shunt has become the standard of care in recent years. Correction of ASDs prevents the

*Parts of this paper were published as abstracts during the European Society of Cardiology Congress in 2009 and in 2010.
Correspondence: Monika Komar Diseases, Institute of Cardiology, Jagiellonian University, John Paul II Hospital, 80 Pradnicka Street, Kraków, Lesser Poland 3I-202, Poland

$\mathrm{Tel}+48 \quad 126142287$

Fax +48 I2 4234376

Email moni_s@interia.pl 
development of pulmonary hypertension, cardiac arrhythmia, and heart failure. ${ }^{1-4}$ The indications for ASD closure in adults, however, are ambiguous. The most controversial issue is selection of candidates for ASD closure who have normal pulmonary artery pressure, absent or negligible clinical symptoms, and are over 40-60 years of age. ${ }^{5-9}$ The closure of ASDs in elderly patients remains controversial. The aim of this study was to evaluate the outcomes of transcatheter closure of secundum ASDs in elderly patients.

\section{Patients and methods Patient population}

Of a total of 488 consecutive patients with ASDs who underwent transcatheter closure over a period of 10 years in our department, 75 patients ( 45 female, 30 male) over 60 years of age with a mean age of $65.3 \pm 15.7(60-75)$ years were analyzed. All patients had an isolated secundum ASD with a mean left-to-right shunt (ratio of pulmonary to systemic

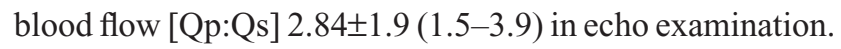
All those patients had the coexisting impairment of physical status, enlargement of right-heart cavity, or pulmonary hypertension. The major demographic characteristics of patients are summarized in Table 1.

\section{Protocol}

A detailed description of the transcatheter closure technique has been given previously., ${ }^{4,5}$ The procedure was performed under local anesthesia. A complete hemodynamic evaluation was performed, as well as right-heart catheterization (measured pulmonary artery pressure and Qp:Qs shunt) and pulmonary arteriography to exclude anomalous pulmonary venous drainage, and coronary angiography. All procedures were performed with continuous transesophageal echocardiographic monitoring. The ASD was sized with a sizing balloon catheter; the stretched diameter of the ASD was defined as the diameter of a balloon that could be withdrawn across the

Table I Demographic characteristics of patients

\begin{tabular}{ll}
\hline & Patients $(\mathbf{n}=\mathbf{7 5})$ \\
\hline Smoking & $15(20 \%)$ \\
Obesity & $18(24 \%)$ \\
Diabetes mellitus & $4(5.3 \%)$ \\
Hypertension & $29(38.6 \%)$ \\
Dyslipidemia & $31(41.3 \%)$ \\
Coronary artery disease & $10(13.3 \%)$ \\
Pulmonary hypertension* & $12(16 \%)$ \\
Atrial fibryillation & $21(28 \%)$ \\
\hline
\end{tabular}

Note: *Measured on right-heart catheterization - mean pulmonary artery pressure over $25 \mathrm{mmHg}$. defect with mild resistance and slight deformity. The selected device was either the same size as the stretched diameter or $1 \mathrm{~mm}$ larger. When the device was deployed across the defect, its position as well as stability were assessed by fluoroscopy and transesophageal echocardiography. Complete ASD closure was defined as no residual shunt; a color Doppler signal width of less than $1 \mathrm{~mm}$ was considered trivial shunting. After the procedure, the patients were treated with $75 \mathrm{mg}$ acetylsalicylic acid and $75 \mathrm{mg}$ clopidogrel once daily for 1 month and then $325 \mathrm{mg}$ acetylsalicylic acid for 11 months to provide antithrombotic protection until full device endothelialization.

The assessment was made in compliance with the following constraints:

- clinical study - within 7 days before the procedure and then at 1,6 , and 12 months after

- transthoracic echocardiographic examination - within 7 days before the procedure and then at 1, 6, and 12 months after

- cardiopulmonary exercise test - within 7 days before the procedure and then at 6 and 12 months after

- quality-of-life measurement - within 7 days before the procedure and then at 12 months after.

\section{Clinical study}

The clinical study was based on subjective opinions of the patients concerning their functional capacity. We assessed the frequency of dyspnea incidences and palpitations.

\section{Transthoracic echocardiographic examination}

Transthoracic echocardiographic examination was performed using a Toshiba Power Vision (Toshiba, Otawara, Japan) machine with a $5.0 \mathrm{MHz}$ multiplane probe, according to a standard protocol including color flow Doppler data. After a comprehensive echocardiographic study of right ventricular and right atrial major and minor dimensions, left ventricular dimensions were measured in end-diastole. M-mode echocardiography from the parasternal long-axis view was used to measure right ventricular dimensions. The apical four-chamber view was used to measure the right atrial and the right ventricle size. The major axis of right atrium was measured from the tricuspid annulus to the atrial superior wall, and the minor axis was measured perpendicularly to the major axis at half of the length of the latter. Each measurement was averaged from five consecutive cardiac cycles. Two independent cardiologists trained in echocardiography agreed on the measurements. Follow-up included 
a complete echocardiographic study with a precise location and measurement of any residual shunt as well as positioning of the device.

\section{Cardiopulmonary exercise test}

In order to objectively assess the clinical and functional status of the patients in all the cases, we performed cardiopulmonary exercise tests. Maximal cardiopulmonary testing was performed on an ergometer cycle. Peak oxygen uptake, carbon dioxide production, and minute ventilation were measured with a computerized breath-by-breath analyzer (Vmax 29тм; CareFusion, San Diego, CA, USA). Patients performed a maximal exercise test using a 1-minute incremental bicycle protocol with a work-rate increment of $10 \mathrm{~W} /$ minute. Criteria for test ending were considered patient exhaustion or a respiratory exchange ratio $\geq 1.09$. A 12-lead electrocardiogram was also monitored throughout the study, and cuff blood pressure was determined manually every 2 minutes. Standard equations were used to generate predicted values for baseline spirometric and peak exercise parameters.

\section{Quality of life}

This objective study was completed with the subjective opinions of the patients concerning their clinical status. In each case, we assessed quality of life using the Short Form (36) Health Survey (SF-36). Patients completed the SF-36, the best-known questionnaire in measuring health status. The number " 36 " refers to 36 questions that concern eight aspects of general health and quality of life, ie, physical function, role - physical, bodily pain, general health, vitality, social function, role - emotional, and mental health.

\section{Statistical analysis}

Continuous data are expressed as means \pm standard deviation, and baseline and follow-up were compared with the paired Student $t$-test. For the comparison of categorical variables, the $\chi^{2}$ test was used. The level of statistical significance was two-sided and set at $P<0.05$. Multivariate analyses, such as multiple forward stepwise regression and canonical correlation, were used to evaluate the parameters affecting improvement of quality of life. Statistical analysis was performed with SPSS version 15.0.0 for Windows (SPSS, Chicago, IL, USA).

\section{Results}

The devices were successfully implanted in all the subjects, with mean procedure time of $37.7 \pm 4.5$ (13-59) minutes and mean fluoroscopy time of $11.2 \pm 9.9$ (6-40) minutes. The defect echo diameter was $17.7 \pm 15.8(12-30) \mathrm{mm}$. The mean balloon-stretched diameter of ASD was 22.4 \pm 7.9 (14-34) $\mathrm{mm}$. The diameter of the implanted devices ranged from 16 to $34 \mathrm{~mm}$. The Amplatzer ${ }^{\mathrm{TM}}$ (St Jude Medical, St Paul, MN, USA) ASD-closure device was used in 45 (60\%) patients, the StarFlex device (NMT Medical Inc, Boston, MA, USA) in five (6.7\%) patients, and the Cardia (Eagan, MN, USA) ASD device in ten (13.3\%) patients. There were ten $(13.3 \%)$ patients with significant coronary problems. Six patients underwent medical therapy, and four patients underwent percutaneous coronary artery intervention using a stent before the transcatheter closure of ASD. There were no serious complications, no deaths, no device embolizations, and no fractures of the device. Minor complications were recorded in ten $(13.3 \%)$ patients with minor venous access bleeding without transfusion. All the patients remained well with no complications or new symptoms at their 12-month follow-up. No patient had any heartrelated hospital admissions. All the patients had a complete 12-month follow-up.

A significant increase in the number of supraventricular (SVE) premature beats/24 hours was noted within 1 month after the procedure. There was a reduction of the number of supraventricular arrhythmias within the follow-up period, so after 12 months of ASD II closure, there were no significant differences from baseline data $(223 \pm 232$ versus $211 \pm 230)$.

\section{Clinical study}

Transcatheter closure of secundum ASD created improvement in the clinical status of the patients in the early follow-up. It caused reduction of breathlessness and palpitation as early as a month after the procedure (Figures 1 and 2).

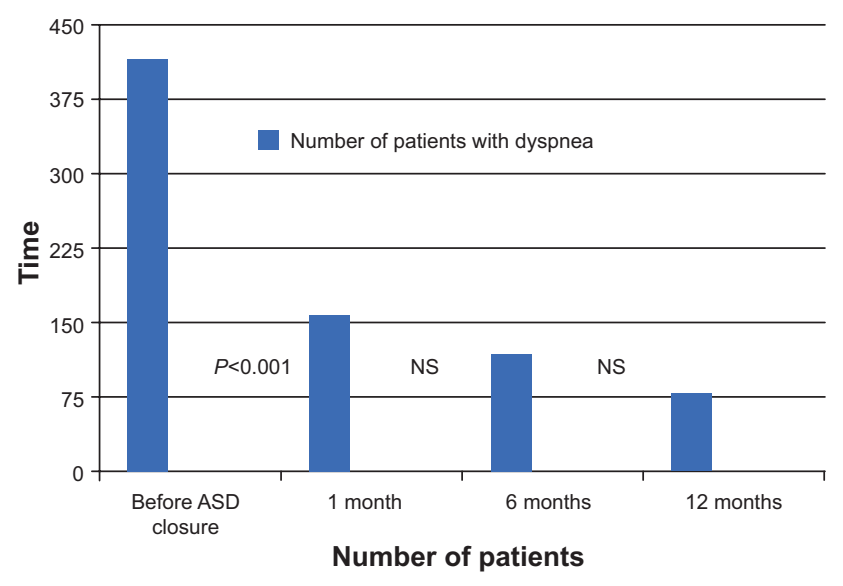

Figure I Frequency of dyspnea before and after ASD closure. Abbreviations: ASD, atrial septal defect; NS, not significant. 


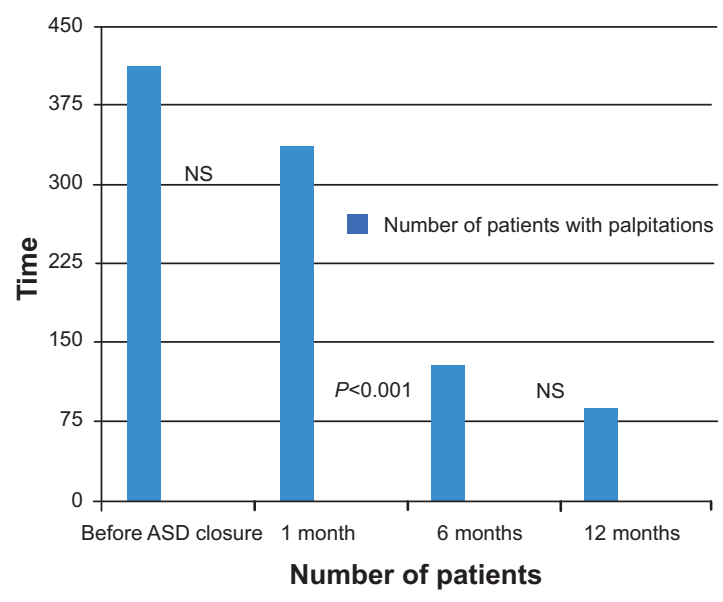

Figure 2 Frequency of palpitations before and after ASD closure. Abbreviations: ASD, atrial septal defect; NS, not significant.

\section{Transthoracic echocardiographic examination}

Directly after the procedure, transthoracic echocardiography showed the residual trivial shunt in seven (9.3\%) subjects, which disappeared in all cases within the 6-month follow-up period. As early as 1 month after the procedure, a significant decrease of the right ventricular dimension and the right atrium dimension was observed. All the analyzed dimensions of the right heart decreased in 67 patients $(89.3 \%)$ (Table 2). The residual patients did not experience changes.

\section{Cardiopulmonary exercise tests}

Significant improvement of exercise capacity was noted at 6 and 12 months after the procedure. Exercise time within 6 months of ASD closure was longer compared to baseline values, and also oxygen consumption increased (Table 3).

\section{Quality of life}

Apart from the objective improvement of physical activity in the cardiopulmonary exercise test, the significant improvement in quality of life in patients based on the SF-36 was also noted. Moreover, an advancement of each aspect of quality of life was observed, with the exception of mental health. The mean SF-36 score increased significantly in 66 (88\%) patients (46.2 \pm 19.1 [5-69]). Total SF-36 scores improved from 20.8 to 61.4 points (Table 4 ).

The canonical correlation analysis showed that the following parameters had an influence on improvement of total SF-36 score: improvement in cardiopulmonary test (prolonged time of exercise, improvement of maximal oxygen consumption $[\mathrm{mL} / \mathrm{kg} / \mathrm{min}]$ ) and reduction in the right heart (right ventricular area $\left[\mathrm{cm}^{2}\right]$, right arterial area $\left.\left[\mathrm{cm}^{2}\right]\right) ; P<0.05$.

The multiple forward stepwise regression analysis revealed that all parameters of the echocardiography study and cardiopulmonary exercise test (improvement of maximal oxygen consumption [mL/kg/min], $F_{7,21}=9.2281, P<0.001$, standard error 2.220) had a strong influence on improvement of total SF-36 score.

\section{Discussion}

Isolated ASDs constitute the second-most common (after bicuspid aortic valve) congenital heart lesion in adults. ${ }^{1,2}$ Surgical closure of ASDs has been practiced for about 45 years. ${ }^{3,4}$ Since the first attempt in 1976, transcatheter closure of secundum ASDs has evolved over the past three decades..$^{5-8}$ Surgical repair of ASDs in patients $>60$ years of age may result in significant mortality and morbidity. Harjula et al reported an operative mortality rate of $6 \%$ and a postoperative morbidity rate of $24 \%$ in the form of major complications. ${ }^{7}$ The hospital stay after surgical repair of

Table 2 Echocardiographic parameters before and after ASD closure

\begin{tabular}{|c|c|c|c|c|c|c|c|}
\hline Parameter & Before ASD & I month after & 6 months after & I 2 months after & $P$-value before & $P$-value before & $P$-value before \\
\hline & closure & ASD closure & ASD closure & ASD closure & versus I month & versus 6 months & versus 12 months \\
\hline $\mathrm{RV}$ diastole $(\mathrm{mm})$ & 35.5 & 26.8 & 24.3 & 24.4 & $<0.001$ & $<0.001$ & $<0.001$ \\
\hline RV systole (mm) & 28.5 & 24.5 & 24.4 & 23.1 & $<0.001$ & $<0.001$ & $<0.001$ \\
\hline RV long axis (mm) & 60 & 55.9 & 55.3 & 54.3 & $<0.001$ & $<0.001$ & $<0.001$ \\
\hline RV short axis $(\mathrm{mm})$ & 39.6 & 34.2 & 32 & 31.9 & $<0.001$ & $<0.001$ & $<0.001$ \\
\hline $\mathrm{RV}$ area $\left(\mathrm{cm}^{2}\right)$ & 19.5 & 17.3 & 15.9 & 12.0 & $<0.001$ & $<0.001$ & $<0.001$ \\
\hline RA long axis (mm) & 44.4 & 39.4 & 39.9 & 39.0 & $<0.001$ & $<0.001$ & $<0.001$ \\
\hline RA short axis (mm) & 42.3 & 33.8 & 34.2 & 33.7 & $<0.001$ & $<0.001$ & $<0.001$ \\
\hline $\mathrm{RA}$ area $\left(\mathrm{cm}^{2}\right)$ & 24.8 & 20.6 & 19.3 & 17.2 & $<0.001$ & $<0.001$ & $<0.001$ \\
\hline LV diastole (mm) & 49.9 & 47.3 & 45.9 & 46.2 & NS & NS & NS \\
\hline LV systole $(\mathrm{mm})$ & 35.4 & 38.5 & 36.1 & 38.1 & NS & NS & NS \\
\hline EF (\%) & 60.4 & 59.4 & 60.1 & 59.5 & NS & NS & NS \\
\hline
\end{tabular}

Abbreviations: ASD, atrial septal defect; RV, right ventricle; RA, right atrium; LV, left ventricle; $E F$, ejection fraction; NS, not significant. 
Table 3 Parameters of cardiopulmonary exercise test before and after ASD closure

\begin{tabular}{|c|c|c|c|c|}
\hline Parameter & $\begin{array}{l}\text { Before ASD } \\
\text { closure }\end{array}$ & $\begin{array}{l}6 \text { months after } \\
\text { ASD closure }\end{array}$ & $\begin{array}{l}\text { I } 2 \text { months after } \\
\text { ASD closure }\end{array}$ & $\begin{array}{l}P \text {-value before } \\
\text { versus } 12 \text { months }\end{array}$ \\
\hline Time of exercise (seconds) & $546 \pm 71$ & $680 \pm 155$ & $834 \pm 265$ & $<0.001$ \\
\hline Heart rate (beats/min) & $149 \pm 28.9$ & $131.2 \pm 30.8$ & $121.4 \pm 38.2$ & $<0.01$ \\
\hline Heart rate\% & $90.5 \pm 10.2$ & $85.3 \pm 12.1$ & $84.9 \pm 15.2$ & $<0.001$ \\
\hline $\mathrm{VO}_{2 \text { peak }}(\mathrm{mL} / \mathrm{kg} / \mathrm{min})$ & $8.2 \pm 3.5$ & $10.1 \pm 8$ & $13.5 \pm 9.7$ & $<0.001$ \\
\hline $\mathrm{VCO}_{2}(\mathrm{~L} / \mathrm{min})$ & $\mathrm{I} .64 \pm \mathrm{I} . \mathrm{I}$ & $1.7 I \pm 0.9$ & $1.78 \pm 0.9$ & $<0.001$ \\
\hline Plus- $\mathrm{O}_{2}$ & $9.5 \pm 1.1$ & $12.1 \pm 2.1$ & $12.9 \pm 2.5$ & $<0.001$ \\
\hline $\mathrm{VD} / \mathrm{VT}$ & $0.20 \pm 0.19$ & $0.17 \pm 0.1$ & $0.17 \pm 0.06$ & $<0.01$ \\
\hline $\mathrm{VE} / \mathrm{VCO}_{2}$ & $30.1 \pm 3.1$ & $24.9 \pm 4.1$ & $25.7 \pm 3.7$ & $<0.05$ \\
\hline $\mathrm{T}_{\mathrm{AT}}$ (seconds) & $376 \pm 70.7$ & $426 \pm 130$ & $499 \pm 105$ & $<0.001$ \\
\hline $\mathrm{VO}_{2 \mathrm{AT}}(\mathrm{mL} / \mathrm{kg} / \mathrm{min})$ & $13.1 \pm 10.0 \mid$ & $15.3 \pm 10.8$ & $16.8 \pm 12.1$ & $<0.001$ \\
\hline $\mathrm{VO}_{2 \mathrm{AT}} \%$ & $37.2 \pm 9.4$ & $42.7 \pm 10.6$ & $42.9 \pm 10.2$ & $<0.001$ \\
\hline
\end{tabular}

Abbreviations: ASD, atrial septal defect; $\mathrm{VO}_{2}$ peak , peak oxygen consumption; $\mathrm{VO}_{2 \mathrm{AT}}$, ventilatory anaerobic threshold; $\mathrm{VCO}_{2}$, production of carbon dioxide; $\mathrm{Plus}_{2} \mathrm{O}_{2}$, oxygen pulse; VD/VT, tidal volume; $\mathrm{VE} / \mathrm{VCO}_{2}$, ventilatory equivalent for $\mathrm{CO}_{2} ; \mathrm{T}_{\mathrm{AT}}$, time to attain anaerobic treasure; $\mathrm{VO}_{2 \mathrm{AT}}$, oxygen consumption in at anaerobic threshold; min, minutes.

ASDs in patients $>60$ years of age ranged from 8 to 20 days (average 11 days). ${ }^{7}$ On the other hand, transcatheter closure of ASD has a low morbidity rate and shorter hospital stays compared to postoperative surgical complications. Morbidity is related to the possible risks of blood transfusions required for surgery, which were not required in our patients undergoing percutaneous ASD closure. However, there have been no reports comparing results, closure rates, morbidity rates, and complications of transcatheter and surgical closure of ASDs at the same institution among patients $>60$ years of age.

The benefits of transcatheter treatment of congenital heart diseases are obvious. First of all, we can avoid the complications of open heart surgery, especially general anesthesia, which is absolutely crucial in elderly patients. Another benefit is avoidance of a surgical scar (commonly called "scar of the human soul" by psychologists) and shorter hospitalization time. ${ }^{8,9}$

Moreover, the closure of ASDs in elderly patients is controversial. Some authors undermine the necessity to correct atrial communications in these cases, based on the argument that the risk involved in the procedure is greater than its benefit. ${ }^{9}$

Based on some analyses, it would be appear that ASDs should be closed when they are identified, irrespective of the patient's age. ${ }^{7-11}$ However, few data are available about the results of this procedure in the elderly population ( $>60$ years of age) with prolonged shunts. An ASD is a congenital heart defect, so if it is diagnosed after the age of 60 years, it is always a question whether the closure is advisable if symptoms are not severe. What is more, symptoms in elderly patients with ASDs are quite common, and can be masked because of the numerous associated diseases.

Transcatheter closure of ASDs is a safe and effective treatment. Over the past few years, an increasing number of elderly patients (age $>60$ years) have been admitted for transcatheter closure to prevent ongoing congestive heart failure from volume overload. ${ }^{9}$

Table 4 Results of the SF-36 before and after ASD closure

\begin{tabular}{llll}
\hline Parameter & Before ASD closure & I2 months after & $P$-value \\
\hline SF-36 total scale & $20.8 \pm 3 I$ & $61.4 \pm 31$ & $P<0.001$ \\
PF-physical function & $8.2 \pm 1.1$ & $10.2 \pm 4.2$ & $P<0.01$ \\
RP-role physical & $6.1 \pm 2.7$ & $10.1 \pm I . I$ & $P<0.01$ \\
BP-bodily pain & $7.0 \pm 4.0$ & $14.2 \pm 4.0$ & $P<0.01$ \\
GH-general health & $4.2 \pm 4.9$ & $11.9 \pm 4.0$ & $P<0.00 \mathrm{I}$ \\
V-vitality & $7.2 \pm 3.3$ & $1 \mathrm{II} .2 \pm 3.3$ & $P<0.0 \mathrm{I}$ \\
SF-social functioning & $9.2 \pm 3.9$ & $14.2 \pm 4.5$ & $P<0.0 \mathrm{I}$ \\
RE-role emotional & $14.1 \pm 7.3$ & $19.1 \pm 8.9$ & $P<0.0 \mathrm{I}$ \\
MH-mental health & $4.2 \pm 4.9$ & $4.7 \pm 4.0$ & $P=0.78$ \\
\hline
\end{tabular}

Abbreviations: ASD, atrial septal defect; SF-36, Short Form (36) Health Survey. 
Our study results demonstrate that device closure of ASDs in the elderly is technically easy, safe, and with minimal complications. We did not encounter any serious complications, such as erosion, device migration, thrombus formation, or embolic events, during the procedure or at follow-up. In our study, supraventricular arrhythmia occurring de novo after device implantation was temporal and disappeared in 1 year's time. None of the rhythm disorders recorded in our patients had an impact on the postoperative period. No additional hospitalizations or other clinical incidences were associated with arrhythmias.

The aim of the study was to evaluate the results of transcatheter closure of ASDs in elderly patients. All those patients had a coexisting impairment of physical status, enlargement of the right-heart cavity, or pulmonary hypertension. No major complications occurred during the hospital stay, which is consistent with the reports in the literature. ${ }^{10-13}$ All patients survived and remained well, with no complications or new symptoms at their 12-month follow-up. No patient has had any heart-related hospital admissions. All the patients completed 12 months of follow-up. In our opinion, even elderly patients with clinical impairment and right-heart enlargement could benefit from ASD closure.

In our study, closure of the ASD resulted in significant improvement of the clinical status of patients in early follow-up. It caused a reduction of breathlessness and palpitation. There were no patients who had not improved; the improvement was even recognized in the group of patients with pulmonary arterial hypertension.

One of the most difficult problems for the treatment of ASDs in elderly patients is comorbid disease. More than a third of patients have systemic hypertension and other systemic diseases, such as diabetes mellitus or cerebral infarction. Cardiac comorbidities, such as pulmonary hypertension, ventricular dysfunction, atrial arrhythmia, and ischemic heart disease, are known to make transcatheter closure more complicated. ${ }^{12,13}$ In our study, ten patients had ischemic heart disease. In four cases, we performed percutaneous transluminal coronary angioplasty with stent implantation before ASD closure, and in six patients we applied pharmacological treatment for the ischemic heart disease.

Some reports have documented that substantial reverse remodeling of the heart after closure improves symptoms and functional status. ${ }^{14-19}$ However, we found a great reduction in right-heart dimensions after device closure. Nearly all patients showed improvement: reduction of symptoms, an improvement in functional and exertional capacity, and significant hemodynamic improvement. Peak oxygen-consumption numbers at baseline in cardiopulmonary exercise tests were correct, and respiratory exchange ratio values were similar for all observation times; we hypothesized that before ASD closure, patients did not exercise maximally and feared more effort, although they were encouraged to exercise by the practitioner in the same way as after ASD closure.

Quality of life improved, as did exercise capacity. The objective clinical status of the patients (cardiopulmonary exercise tests, echo examination) improved as well as their subjective opinions of their quality of life. Therefore, we believe that it is really worthwhile to close ASDs in elderly patients with coexisting impairment of physical status, enlargement of right-heart cavity, or pulmonary hypertension. Regardless of the patient's age, clinical improvement is possible. Right-heart remodeling and improvement in quality of life and physical status can occur in those elderly patients. Naturally, each case should be analyzed and qualified individually.

\section{Study limitations}

The major limitations of the present study were its nonrandomized nature and the lack of a control group.

\section{Conclusion}

Closure of ASDs in elderly patients resulted in significant clinical and hemodynamic improvement after percutaneous treatment, which requires long-term follow-up. Right-heart remodeling can occur in patients $>60$ years of age.

\section{Disclosure}

The authors report no conflicts of interest in this work.

\section{References}

1. Campbell M. Natural history of atrial septal defect. Br Heart J. 1970;32:820-826.

2. Hoffman JI, Kaplan S. The incidence of congenital heart disease. J Am Coll Cardiol. 2002;39:1890-1900.

3. Murphy JG, Gersh BJ, McGoon MD, et al. Long-term outcome after surgical repair of isolated atrial septal defect. Follow-up at 27 to 32 years. $N$ Engl J Med. 1990;323:1645-1650.

4. Butera G, Carminati M, Chessa M, et al. Percutaneous versus surgical closure of secundum atrial septal defect: comparison of early results and complications. Am Heart J. 2006;151:228-234.

5. Fischer G, Stieh J, Uebing A, Hoffmann U, Morf G, Kramer HH. Experience with transcatheter closure of secundum atrial septal defects using the Amplatzer septal occluder: a single centre study in 236 consecutive patients. Heart. 2003;89:199-204.

6. Amin Z, Hijazi ZM, Bass JL, Cheatham JP, Hellenbrand WE, Kleinman CS. Erosion of Amplatzer septal occluder device after closure of secundum atrial septal defects: review of registry of complications and recommendations to minimize future risk. Catheter Cardiovasc Interv. 2004;63:496-502. 
7. Harjula A, Kupari M, Kyösola K, et al. Early and late results of surgery for atrial septal defect in patients aged over 60 years. J Cardiovasc Surg (Torino). 1988;29:134-139.

8. Miyaji K, Furuse A, Tanaka O, Kubota H, Ono M, Kawauchi M. Surgical repair for atrial septal defect in patients over 70 years of age. Jpn Heart J. 1997;38:677-684.

9. Attie F, Rosas M, Granados N, Zabal C, Buendía A, Calderón J. Surgical treatment for secundum atrial septal defects in patients $>40$ years old. A randomized clinical trial. J Am Coll Cardiol. 2001;38:2035-2042.

10. Humenberger M, Rosenhek R, Gabriel H, et al. Benefit of atrial septal defect closure of adults: impact of age. Eur Heart J. 2011;32: 553-560.

11. Harper RW, Mottram PM, McGaw DJ. Closure of secundum atrial septal defects with the Amplatzer septal occluder device: techniques and problems. Catheter Cardiovasc Interv. 2002;57:508-524.

12. Masura J, Gavora P, Podnar T. Long-term outcome of transcatheter secundum-type atrial septal defect closure using Amplatzer septal occluders. J Am Coll Cardiol. 2005;45:505-507.

13. Veldtman GR, Razack V, Siu S, et al. Right ventricular form and function after percutaneous atrial septal defect device closure. $J$ Am Coll Cardiol. 2001;37:2108-2113.
14. Galal MO, Wobst A, Halees Z, et al. Peri-operative complications following surgical closure of atrial septal defect type II in 232 patients - a baseline study. Eur Heart J. 1994;15:1381-1384.

15. Brochu MC, Baril JF, Dore A, Juneau M, De Guise P, Mercier LA. Improvement in exercise capacity in asymptomatic and mildly symptomatic adults after atrial septal defect percutaneous closure. Circulation. 2002;106:1821-1826.

16. Roos-Hesselink JW, Meijboom FJ, Spitaels SE, et al. Excellent survival and low incidence of arrhythmias, stroke and heart failure long-term after surgical ASD closure at young age. A prospective follow-up study of 21-33 years. Eur Heart J. 2003;24:190-197.

17. Horvath KA, Burke RP, Collins JJ Jr, Cohn LH. Surgical treatment of adult atrial septal defect: early and long-term results. $\mathrm{J} \mathrm{Am} \mathrm{Coll} \mathrm{Cardiol.}$ 1992;20:1156-1159.

18. Yüce M, Ozer O, Cakıcı M, et al. [Closure of secundum atrial septal defects by the Amplatzer occluder device]. Turk Kardiyol Dern Ars. 2011;39:35-40. Turkish

19. Pieculewicz M, Podolec P, Przewlocki T, et al. Closure of atrial septal defect in the elderly patients. Eur Heart J. 2009;30 Suppl 1:2005.
Clinical Interventions in Aging

\section{Publish your work in this journal}

Clinical Interventions in Aging is an international, peer-reviewed journal focusing on evidence-based reports on the value or lack thereof of treatments intended to prevent or delay the onset of maladaptive correlates of aging in human beings. This journal is indexed on PubMed Central, MedLine,

\section{Dovepress}

CAS, Scopus and the Elsevier Bibliographic databases. The manuscript management system is completely online and includes a very quick and fair peer-review system, which is all easy to use. Visit http://www.dovepress. $\mathrm{com} /$ testimonials.php to read real quotes from published authors. 